\title{
Contribuições do escritório de gerenciamento de projetos públicos na gestão para resultados
}

Marcelo Torres Pinheiro e Mônica Aparecida da Silva Rocha

\section{Introdução}

A busca por resultados de desempenho tem transformado as administrações dos setores públicos, na maioria dos países democráticos. No Brasil, essa crescente busca por resultados vem sensibilizando, nos últimos anos, administrações públicas em nível federal, estadual e municipal. Algumas administrações mais alinhadas aos preceitos da Nova Gestão Pública estão se organizando para promoverem melhor desempenho em seus governos - gastando de forma mais criteriosa e responsável os recursos públicos -, visando atender precípua e estrategicamente às demandas da população.

Nas últimas duas décadas, é possível notar que os governos estão se adaptando a modelos de cunho gerencialista, que prezam pelo melhor desempenho e pela adoção de formatos que proporcionem reconhecidos resultados, ou seja, mais gerenciais na condução dos projetos públicos. Nesse aspecto, conforme observam Cohen e Franco (2004), temos um conjunto de fatores que concorrem para 
melhorar importantes indicadores, como o de eficiência, ou seja, a relação existente entre os produtos e os custos dos insumos, notadamente questões de processo; e os relacionados à eficácia, ou seja, relativos ao grau em que são alcançados objetivos e metas de dado projeto, em determinado período de tempo, independentemente dos custos, caracterizado pelo produto da ação.

No Brasil, o sistema de avaliação de políticas públicas baseado no desempenho, considerando os indicadores de eficiência e eficácia, ainda não está consolidado nas administrações, apesar de novas iniciativas, oriundas de uma visão mais gerencial, demonstrarem que esse é um caminho que os governos vêm buscando trilhar. Pela Constituição Federal de 1988, quem deve monitorar e acompanhar a execução dos projetos públicos é um órgão interno específico (controle interno) e outros externos, como os tribunais de contas estaduais e o federal (Tribunal de Contas da União - TCU). Apesar desses tribunais tradicionalmente avaliarem a conformidade normativa, os resultados relacionados ao desempenho ainda são passivos de análises subjetivas e, muitas vezes, desassociadas do conjunto das políticas públicas, em face da precariedade da existência de planos estratégicos de longo prazo que deveriam balizar, via diretrizes estratégicas, o estabelecimento de objetivos de desenvolvimento socioeconômico em níveis locais e regionais.

Organismos internacionais, como o Banco Interamericano de Desenvolvimento (BID) e o Centro Latinoamericano de Administração para Desenvolvimento (Clad), que acompanham a evolução da gestão pública, ressaltam que - sobre o conceito de Gestão para Resultados (GpR) existem alguns importantes fatores a serem observados: compromisso e comprometimento amplo com as políticas públicas nos níveis horizontais e verticais; a gestão do processo de mudanças; o apoio e o envolvimento das autoridades políticas; a iniciativa e o comprometimento gerencial; a gestão contínua do tempo; a adaptação ao ambiente, com atenção às especificidades; a visão global com implantação local; o desenvolvimento equilibrado e sustentável; a análise atenciosa e o uso devido da informação; a aprendizagem organizacional e individual; e o plano de trabalho enfatizando o alcance dos resultados (SERRA, 2008).

Esse artigo se baseia na dissertação de mestrado do primeiro autor, que buscou averiguar a relação entre a adoção e a implementação do gerenciamento de projetos em administrações públicas estaduais e a relação desta metodologia com a melhoria da eficiência e da eficácia nos resultados. No presente trabalho, pretende-se discutir em que medida o gerenciamento de projetos contribui com a gestão orientada para resultados, e verificar a hipótese de que com a adoção e o uso do gerenciamento de projetos, difundido pelo escritório de gerenciamento de projetos públicos, é possível incorrer na melhoria dos resultados de gestão, atendendo aos princípios gerenciais aludidos pela Nova Gestão Pública e ao preceito constitucional da eficiência e eficácia nas administrações públicas.

Ainda no escopo dessa discussão, notase a importância política e administrativa de duas questões: a primeira diz respeito a um déficit metodológico relativo à implementação de políticas públicas nas administrações públicas brasileiras, que vise fornecer elementos teóricos, ferramentais e técnicos que auxiliem os gestores na identificação, elaboração e execução de projetos públicos, sendo que, em tese, o propósito dessa metodologia seria o de 
alinhar conceitos e procedimentos que sustentem a implementação das políticas públicas; a segunda questão diz respeito ao monitoramento e à avaliação sistêmica que permitam um controle da gestão orientada para resultados de desenvolvimento crescente.

Após essa introdução, seguem as abordagens teóricas que sustentam e ambientam o conjunto de mudanças transformadoras, interpretativas e de novas conceituações que proporcionaram a entrada do gerencialismo focado em objetivos de resultados nas administrações públicas. Em seguida, de forma sucinta, é abordado o método empregado e os procedimentos inerentes à pesquisa de campo.

Os resultados coletados e as análises são expostos de forma sintética, mas centrada no julgamento da hipótese lançada. A última parte traz as conclusões suscitadas pelo estudo e as considerações julgadas relevantes, visto que os aspectos metodológicos introduzidos pelo gerenciamento de projetos guardam relação com fatores primordiais relativos à implementação de políticas públicas.

Nova gestão pública e a implementação de políticas públicas

No início dos anos 1980, começou um movimento de alcance internacional para a reestruturação do papel do Estado e a implantação de um modelo de gestão pública orientada para resultados, que genericamente denominou-se de Nova Gestão Pública (termo utilizado para designar o novo modelo de administração pública, oriundo da expressão inglesa New Public Management), também chamada de administração gerencial. Esse modelo vem dando forma às mudanças introduzidas na administração pública de alguns países da
Organização Europeia para o Comércio e Desenvolvimento (OCDE), sobretudo na Grã-Bretanha e também na América Latina (ABRÚCIO, 1997).

Esse movimento propaga, em parte, a aplicação do modelo de gestão privada às organizações públicas, enfatizando a importância do empreendedorismo, da eficiência, da eficácia, e de estratégias planificadas de resultados voltadas para o cliente-cidadão.

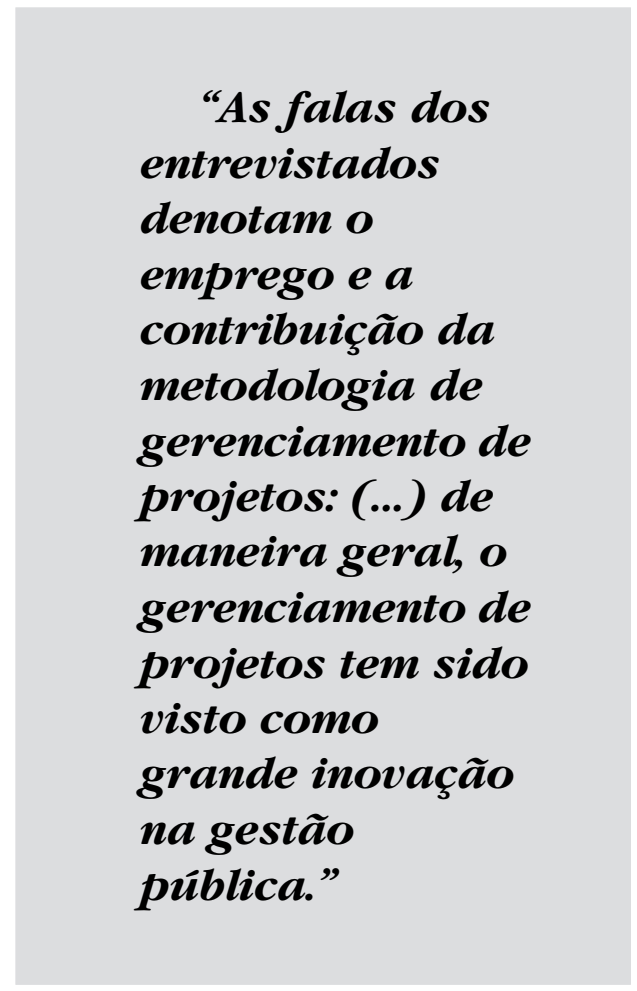

A implementação de ações estratégicas torna-se fundamental para validar a revisão dos processos e a eminente reformulação, com adoção de inovações que sustentem a nova dinâmica requerida pela administração pública. Tais processos remetem a uma melhor compreensão do papel exercido pelo gerenciamento de projetos públicos no âmbito do uso de novos 
recursos, principalmente os metodológicos, que buscam melhorar os processos, tendo em vista sua utilização como instrumento de execução do Plano Plurianual (PPA).

Esta nova ordem nas administrações públicas está guiando as novas políticas públicas, em que o termo eficiência passa a ser visto como o principal objetivo de qualquer política pública, aliada impreterivelmente à legitimidade e autonomia das instituições políticas. Por sua vez, Martins (2004) observa certo deslumbramento por parte de alguns governos com a Nova Gestão Pública, que surgiu como portadora de modelos de gestão mais orgânicos, servindo de novo paradigma a ser seguido e provocando - de certo modo - o mesmo fascínio que o modelo burocrático ortodoxo havia provocado anteriormente.

Tal fascínio, porém, não subjuga a burocracia, que continua exercendo papel fundamental nas administrações públicas. $\mathrm{O}$ apelo gerencial força, por sua vez, as revisões dos processos. O papel do planejamento e seu vínculo ao orçamento ganha compreensão e pertinência, trazendo à luz discussões contemporâneas, que remetem ao uso dos recursos tecnológicos de gestão e novas práticas, que prezam pelo desempenho e a produtividade.

Entre os motivos que levaram a essa reavaliação do papel do Estado perante a sociedade e a economia estão, segundo alguns autores (AuCOIN, 1995; Hood, 1995; Pollitt \& Bouckaert, 2002), questões como: crise fiscal, crise do welfare state, ineficiências do modelo de administração burocrático, busca por investimentos transnacionais, globalização dos mercados e alto grau de avanços das tecnologias de comunicação e informação.

A Figura 1 ilustra esse processo a partir da crise do Estado. Um conjunto de fatores favorece a condução de "posturas" que prezam por uma gestão orientada para resultados.

Como colocado por Silva (2007) e por outros autores, a crise do Estado torna-se evidenciada pelas crises: fiscal, econômica (modo de intervenção do próprio Estado), do modelo de administração burocrática e da governança. Esse conjunto de fatores favorece os defensores de um novo modelo para a administração pública.

No caso do Brasil, Bresser Pereira (2005) menciona que a reforma da gestão pública não subestimou os elementos patrimonialistas e clientelistas ainda existentes no Estado brasileiro, mas buscou firmemente avançar em direção a uma gestão mais autônoma e mais responsabilizada perante a sociedade, com instrumentos que visavam proporcionar mais eficiência e modernidade ao governo.

De acordo com Abrúcio e Gaetani (2006), os avanços da reforma da gestão pública, em 1995, em diferentes estados, mostram que quatro questões se destacaram: 1) a realização de encontros de secretários estaduais de administração, apoiados pelo então ministro Bresser Pereira; 2) a aderência dos estados à adoção de modelos gerenciais; 3) os ajustamentos modernos que certos governos estaduais realizaram - reformas administrativas; e 4) entre os anos de 2003 e 2006, houve uma migração de técnicos de alto escalão - partícipes do então Governo de Fernando Henrique Cardoso -, que emprestaram seus conhecimentos e experiências aos estados que estavam se organizando para implementar a gestão pública orientada para resultados (GpR).

O modelo de GpR se tornou uma das partes centrais da agenda de reformas administrativas e vem sendo adotado como uma forma de atingir melhores níveis de accountability, responsividade e qualidade (Bouckaert \& Halligan, 2008 apud 


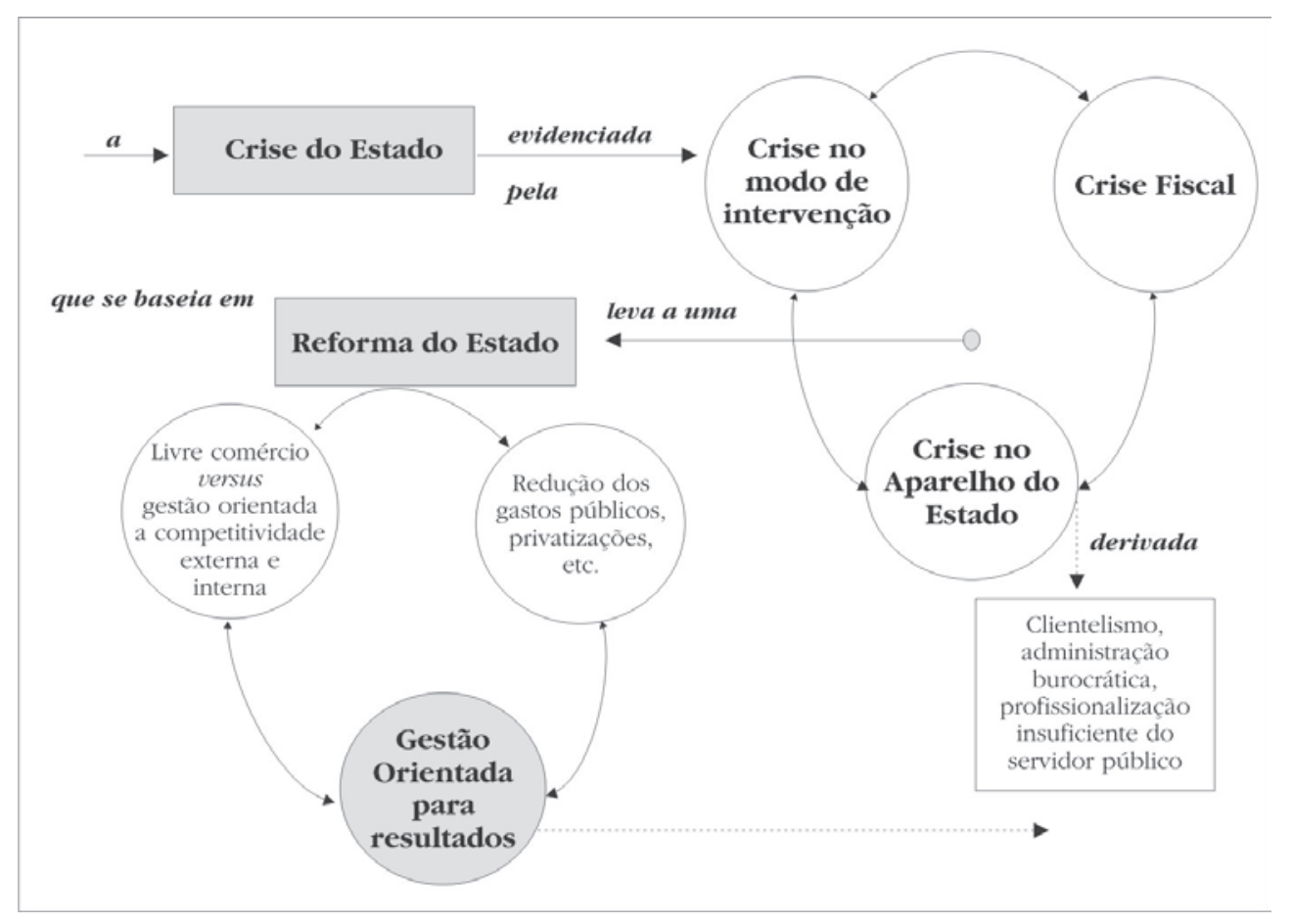

Fonte: Silva (2007)

Figura 1: Da crise do Estado à Gestão Orientada para Resultados

Perdicaris, 2009). Cabe observar que tal modelo é conceitual, paradigmático e mexe com muitos fatores arraigados na administração pública, entre eles, a cultura organizacional do setor público. Isso porque muda a abordagem central, passando da atenção às questões meio, ou meramente burocrática e de conformidade, para se deter, com ênfase, nas entregas e nos resultados da gestão - os produtos das políticas públicas.

O modelo aberto de gestão para resultados no setor público, segundo o Banco Interamericano de Desenvolvimento e o Centro Latinoamericano de Administração para o Desenvolvimento, está definido como um marco conceitual cuja função é a de facilitar às instituições públicas a direção efetiva e integrada do processo de criação de valor público, otimizando e provendo melhorias na eficácia, eficiência e efetividade, visando à consecução dos objetivos de gestão governamental (BID/ Clad, 2007).

Uma questão-chave para a compreensão de como se realizam as implementações dos programas e projetos passa pela análise de cenários. Há situações que envolvem diferentes níveis de complexidades e incertezas, tanto no ambiente interno (organização executora e parceiros) quanto no ambiente externo, no macroambiente político e institucional em que os projetos se realizam e que envolvem diversos stakeholders.

Entende-se que a implementação é um processo complexo, com importantes 
partes envolvendo decisões e escolhas políticas, complementada com requisitos de competência técnica e pelo uso de metodologias e recursos diversos. Tem no comando das variadas ações pessoal qualificado e com habilidades específicas para conduzir com sucesso a execução, a fim de que a mesma atenda aos objetivos e metas previamente acordados e que produza valor público aos beneficiados. Diante disso, faz sentido encontrar um conjunto formal, organizado e testado de recursos de implementação, como a metodologia de gerenciamento de projetos, para prover organização, método e recursos.

\section{O gerenciamento de projetos e o escritório de gerenciamento de projetos públicos}

O gerenciamento de projetos ganhou visibilidade nas administrações a partir do final do século XX, em virtude de grandes transformações provocadas pela globalização e pela introdução de novas tecnologias de informação e comunicação - que deram uma nova dinâmica aos processos de inovação tecnológica -, o que obrigou muitas empresas e a própria administração pública a buscar meios de corresponder de forma mais assertiva, eficiente e eficaz às novas demandas impostas pelos mercados.

O Guia do Conjunto de Conhecimentos em Gerenciamento de Projetos editado pelo Project Management Institute, conhecido por $\mathrm{PMBOK}^{\circledR}$, em sua edição de 2004, apresenta a seguinte definição de projeto: um esforço temporário para alcançar um objetivo específico (resultado exclusivo). Para o Project Management Institute $\left(\mathrm{PMI}^{\circledR}\right)$, a definição de gerenciamento de projetos pode ser assim compreendida: é a aplicação de conhecimentos, habilidades, ferramentas e técnicas num conjunto amplo de atividades (meio), com o propósito de atender aos requisitos (fim) do projeto. Outra instituição transnacional, como a Accrediting Professionals Management Group (APMG), trata a questão dando ênfase ao gerenciamento em ambientes controlados.

Quanto aos aspectos metodológicos, o $\mathrm{PMBOK}^{\circledR}$ (2004) define o ciclo de vida do projeto, delimitado pelos grupos de processo: iniciação, planejamento, execução, controle e avaliação, e encerramento. Este ciclo abriga 44 processos gerenciáveis que se distribuem por nove áreas de conhecimento: integração, escopo, prazos, custos, qualidade, recursos humanos, comunicação, riscos e aquisições.

São nove as áreas de conhecimentos específicos que agrupam os elementos que dão entrada ao uso de ferramentas e técnicas, que podem estar presentes em momentos diferentes do ciclo de vida do projeto. Os principais objetivos característicos das áreas do gerenciamento são: Escopo - administrar a inserção de atributos e características específicas do projeto e do(s) produto(s) do projeto; Tempo - proporcionar que o projeto se finalize no tempo proposto; Custo atender às estimativas de custos, ora aprovados; Comunicação - proceder à geração, coleta, armazenamento e distribuição das informações do projeto; Recursos Humanos - garantir e viabilizar o trabalho da equipe do projeto; Qualidade - atender às especificações do projeto; Riscos - identificação, análise, monitoramento e controle dos riscos inerentes; Aquisições - garantir compras de produtos e prestação de serviços em conformidade às necessidades do projeto; Integração - concertar a execução das demais áreas de planejamento do projeto.

O escritório de projetos ou escritório de gerenciamento de projetos (EGP) pode ser entendido como uma unidade 
organizacional que centraliza e coordena o gerenciamento de projetos sob seu domínio. Assume, entre outras funções, o apoio ao planejamento dos projetos estratégicos e o acompanhamento da execução. Os gerentes de carteiras de projetos interagem constantemente com os gerentes de projetos que estão nos órgãos setoriais, por meio de reuniões periódicas e análise do progresso da implementação, visando facilitar a consecução dos mesmos, reforçando um dos principais objetivos do EGP, que é o de prover informações qualificadas para a tomada de decisões.

Cota (2011) observa que ao longo dos últimos anos os EGP prosperaram e criaram valor perceptível para algumas instituições, enquanto outros perderam força e apoio. Grande desafio é encontrar um caminho de crescente ganho de maturidade e fortalecimento das práticas consagradas, visto que as organizações também estão em permanente mudança.

O PMI ${ }^{\circledR}$ edita um guia específico para projetos com viés público, ou seja, projetos de governo. Segundo o Government Extension to the $\mathrm{PMBOK}^{\circledR}$ guide third Edition (2006), projetos do governo são geralmente considerados como tendo características únicas, quando comparados com os do setor privado. A equipe de gerência do projeto deve reconhecer as especificidades dos projetos públicos, como a de restrições legais, incluindo o uso dos recursos inclusive na forma das aquisições, publicização, controle pela imprensa e tipificação da prestação de contas ao público.

Para Rosa (2007), as principais diferenças observadas no gerenciamento de projetos públicos, em relação aos projetos privados, são os critérios de seleção com viés predominantemente social e não lucrativos, o ciclo anual do orçamento (ano fiscal), em que atrasos podem significar perdas de recursos. E, ainda, a influência exercida pelo ciclo eleitoral, com restrições legais específicas, além de ser objeto de regulação intensa (Lei no 8.666/93, das Licitações e Contratos Públicos e a Lei de Responsabilidade - LC 101/2000).

Conforme o PMBOK Government Extension (2006), escritórios de gerenciamento de projetos públicos (EGPP) podem ser vitais para o sucesso dos projetos do governo. A capacidade de fornecer

“Apenas no
Governo do Estado
de Minas Gerais é
possível afirmar
que bá uma
política definida
de recursos
bumanos que
considera a gestão
do desempenbo."

informações sobre o projeto até a data (up-to-date) pode ser muito importante para a continuação do projeto e o sucesso da transição de uma fase para outra.

\section{Metodologia}

Este trabalho é resultado de uma pesquisa de abordagem qualitativa, com 
objetivos exploratórios, que teve por finalidade compreender de que maneira técnicas, processos e ferramentas estão sendo empregados no gerenciamento de projetos públicos, com vistas a uma possível contribuição à Gestão para Resultados. Neste trabalho o procedimento utilizado foi o do levantamento de dados obtidos por meio da interrogação dos atores - participantes qualificados, entrevistas semiestruturadas e a aplicação de questionários semielaborados, além da coleta de material bibliográfico in loco.

As questões fechadas foram tabuladas e receberam tratamento quantitativo básico, enquanto que as questões abertas foram analisadas conforme a fala dos informantes da pesquisa. Após a tabulação e apuração das observações - dadas as representatividades de certas evidências -, estas foram agrupadas e comparadas aos dados apresentados pelas pesquisas de benchmarking em gerenciamento de projetos (conduzidas pelos Chapters brasileiros, que são os representantes estaduais brasileiros do PMI ${ }^{\circledR}$ ) e ao modelo de referência de gestão para resultados do BID/Clad (2007).

Foram realizados agendamentos com gestores e técnicos disponibilizados para a participação na pesquisa. A semana de coleta de dados correspondeu à última do mês de novembro de 2010 e a primeira do mês de dezembro do mesmo ano. Este trabalho se deu por meio de pesquisa de campo, ou seja, aquela que ocorre no ambiente dos sujeitos pesquisados, utilizando-se de duas técnicas: observação direta intensiva (observação e entrevista) e observação direta extensiva (aplicação de questionários).

Selecionamos governos estaduais que apresentaram um conjunto de variáveis semelhantes, mostradas no Quadro 1, e que optaram por implantar escritórios de gerenciamento de projetos, alvo central dessa investigação.

Cabe salientar também que a repercussão do modelo de modernização administrativa implantado pelo Governo do Estado de Minas Gerais, denominado Choque de Gestão, despertou grande interesse por parte de vários governos estaduais e municipais em conhecer a experiência mineira e seguir algumas iniciativas, entre as quais, a implantação do EGP. Como o escopo do estudo se sustenta nos pilares da gestão pública orientada para resultados, foram necessários elementos indicativos consistentes e alinhados, a fim de sustentar a seleção da amostra.

No questionário principal (com 50 questões) utilizou-se a escala do tipo Likert, cuja principal vantagem é proporcionar escolha ao respondente, conforme uma escala de valores que melhor represente sua opinião a respeito daquilo que está sendo pesquisado. As questões na escala do tipo Likert objetivam avaliar o grau de concordância ou discordância dos respondentes, conforme a disposição de perguntas conceituais e posicionamentos afirmativos ou negativos que interessam ao pesquisador e que norteiam o estudo a ser explorado. Nesta pesquisa, foi utilizada uma escala de graus diametralmente opostos, com a opção "discordo totalmente" equivalendo a três pontos negativos (-3) e a opção "concordo totalmente" equivalendo a três pontos positivos $(+3)$, sendo zero o ponto neutro (equivalente à ausência de opinião).

Além do questionário citado, também foi elaborado outro questionário de apoio, com 118 perguntas conjugadas, denominado Questionário de Recursos Utilizados no Gerenciamento de Projetos, reunindo técnicas, processos e ferramentas identificados no $\mathrm{PMBOK}^{\circledR}$ (2004). Esse questionário 
Quadro1: Enquadramento seletivo dos atributos eletivos dos três estados selecionados para o estudo

\begin{tabular}{|l|c|c|c|}
\hline Atributos & $\begin{array}{c}\text { Minas } \\
\text { Gerais }\end{array}$ & $\begin{array}{c}\text { Espírito } \\
\text { Santo }\end{array}$ & $\begin{array}{c}\text { Rio de } \\
\text { Janeiro }\end{array}$ \\
\hline $\begin{array}{l}\text { Planejamento estratégico de longo prazo } \\
\text { institucionalizado }\end{array}$ & $\begin{array}{c}\text { PMDI } \\
\text { Desde 1995 }\end{array}$ & $\begin{array}{c}\text { ES 2025 } \\
\text { Desde 2005 }\end{array}$ & $\begin{array}{c}\text { RJ 2007/27 } \\
\text { Desde 2007 }\end{array}$ \\
\hline Reforma administrativa com foco gerencial & $\begin{array}{c}\text { A partir de } \\
2003\end{array}$ & $\begin{array}{c}\text { A partir de } \\
2004\end{array}$ & $\begin{array}{c}\text { A partir de } \\
2007\end{array}$ \\
\hline $\begin{array}{l}\text { Agenda positiva; modelos de accountability e trans- } \\
\text { parência pública; escritório de gerenciamento de } \\
\text { projetos central; procedimentos administrativos } \\
\text { aderentes à Gestão para Resultados; sistema de } \\
\text { monitoria e avaliação institucionalizado }\end{array}$ & Sim & Sim & \\
\hline
\end{tabular}

Fonte: Elaborado pelo primeiro autor

agrupou 48 técnicas, 47 processos e 23 ferramentas. As perguntas foram conjugadas, sendo a primeira para responder se conhece ou não o recurso e, a segunda, se o utiliza (com as opções: nunca, às vezes e sempre).

Cabe observar que os questionários não foram testados previamente, visto que não se identificou outro ator (governo estadual) que agrupasse as características requeridas.

O falseamento aludido no método foi planejado em dois instrumentos de coleta, no questionário principal e na entrevista. Das 50 questões do questionário principal, 15 foram falseadas intencionalmente, ou seja, inverteu-se propositalmente a orientação (caso do GpR BID/Clad) ou contrariou-se a tendência apontada pelo Estudo 2010 de Benchmarking dos Chapters Brasileiros do PMI. Essas questões foram distribuídas aleatoriamente, com o propósito de medir a interpretação do respondente.

$O$ primeiro estado a ser visitado foi Minas Gerais, seguido pelo Espírito Santo e Rio de Janeiro. Foram quatorze entrevistas no total: sete com gestores públicos e sete com técnicos administrativos, que não ocupavam cargo de gestão. Todas as entrevistas foram gravadas com consentimento dos entrevistados.

O Quadro 2 faz uma comparação dos aspectos funcionais dos EGP pesquisados.

\section{Resultados e análises}

Vale destacar que foram considerados os pesos conforme o grau de concordância ou discordância nos dados coletados e organizados no processo de tabulação do questionário principal de 50 questões, variando conforme a intensidade: concordo parcialmente (de $0 \mathrm{a}+1)$, concordo (de $1 \mathrm{a}$ 2) e concordo totalmente (de 2 a 3); e discordo parcialmente (de 0 a -1 ), discordo $(-1$ a -2$)$ e discordo totalmente $(-2$ a -3$)$. Os dados apontaram os seguintes resultados: concordâncias esperadas com média de +1,42 (faixa de concordo) e discordâncias esperadas com média de -1,68 (faixa de discordo). Logo, ambos os resultados ficaram dentro do previsto e na faixa intermediária, ou seja, isso traduz que os entrevistados concordaram com o que se esperava que eles concordassem e discordaram das 
questões que também despertaram a expectativa de que discordassem.

Quanto às entrevistas, o tempo somado representou 12 horas e 50 minutos de gravações, equivalendo em média a 54 minutos por entrevista. As entrevistas foram individuais e em local reservado para este fim.

A primeira questão explorou o tema planejamento e observou-se que todos os entrevistados deram bastante ênfase ao fato de poderem contar com um planejamento de referência (planejamento estratégico). A noção da construção do desenvolvimento a partir do arranjo das políticas públicas também se evidencia pela fala dos entre- vistados. Destacam-se as seguintes falas dos entrevistados: o plano de longo prazo facilita a delimitação de áreas a serem trabalhadas com mais intensidade em períodos plurianuais, e os projetos prioritários são classificados como estruturantes, proporcionando mais efetividade de resultados em relação ao plano de longo prazo.

A segunda pergunta visou compreender a disponibilização dos recursos para se implementar as políticas públicas. Nos três estados pesquisados, os projetos estruturantes - aqueles escolhidos como estratégicos pelo governo central em dado período - possuem a prerrogativa da garantia dos recursos para sua execução.

Quadro 2: Quadro comparativo dos aspectos funcionais dos escritórios de gerenciamento de projetos (EGP) dos estados pesquisados

\begin{tabular}{|c|c|c|c|c|}
\hline \multicolumn{2}{|c|}{$\begin{array}{c}\text { Caracteristicas e } \\
\text { atributos dos escritórios } \\
\text { de gerenciamento de projetos }\end{array}$} & \multirow{2}{*}{$\begin{array}{l}\begin{array}{c}\text { Governo do Estado } \\
\text { de Minas Gerais }\end{array} \\
\begin{array}{l}\text { Secretaria de Estado de } \\
\text { Planejamento e Gestào }\end{array}\end{array}$} & \multirow{2}{*}{$\begin{array}{c}\begin{array}{c}\text { Governo do Estado } \\
\text { do Espirito Santo }\end{array} \\
\begin{array}{c}\text { Secretaria Extraordinária de } \\
\text { Gerenciamento de Projetos }\end{array}\end{array}$} & \multirow{2}{*}{$\begin{array}{c}\begin{array}{c}\text { Governo do Estado } \\
\text { do Rio de Janeiro }\end{array} \\
\text { Secretaria de Estado da } \\
\text { Casa Civil }\end{array}$} \\
\hline \multirow{10}{*}{ 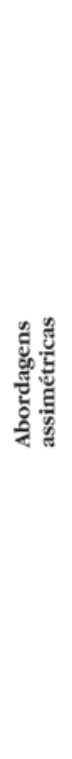 } & Localização no governo & & & \\
\hline & Cargo do servidor & Monitor de Projetos & Gestor de Projetos & Analista de Projetos \\
\hline & Qualificação do servidor & $\begin{array}{l}\text { Nivel superior em } \\
\text { Administração Pública, } \\
\text { concursado. }\end{array}$ & $\begin{array}{l}\text { Nivel superior (diverso), } \\
\text { concursado. }\end{array}$ & $\begin{array}{l}\text { Nivel superior (diverso), } \\
\text { contratado. }\end{array}$ \\
\hline & $\begin{array}{l}\text { Exigência de capacitação } \\
\text { específica para atuação } \\
\text { na área }\end{array}$ & $\begin{array}{c}\text { Sim, Escola de Governo da } \\
\text { Fundação João Pinheiro, curso } \\
\text { de Administração Pública. }\end{array}$ & $\begin{array}{l}\text { Sim (cursos oferecidos aos } \\
\text { servidores efetivos). }\end{array}$ & $\begin{array}{l}\text { Sim (prérequisito para } \\
\text { contratação). }\end{array}$ \\
\hline & $\begin{array}{l}\text { Atividades do Ciclo do } \\
\text { Projeto }\end{array}$ & $\begin{array}{l}\text { Planejar, monitorar, liberar } \\
\text { recursos, avaliar, finalizar. }\end{array}$ & $\begin{array}{l}\text { Planejar, monitorar, avaliar, } \\
\text { finalizar. }\end{array}$ & $\begin{array}{l}\text { Planejar, monitorar, } \\
\text { avaliar, finalizar. }\end{array}$ \\
\hline & $\begin{array}{l}\text { Execução dos projetos e } \\
\text { gerenciamento das } \\
\text { atividades }\end{array}$ & $\begin{array}{l}\text { Pelos órgàos setoriais do } \\
\text { governo }\end{array}$ & $\begin{array}{c}\text { Pelos órgàos setoriais do } \\
\text { governo e empresas contratadas }\end{array}$ & $\begin{array}{l}\text { Pelos órgãos setoriais do } \\
\text { governo }\end{array}$ \\
\hline & $\begin{array}{l}\text { Oferta de capacitação } \\
\text { específica pelo órgão } \\
\text { gestor }\end{array}$ & $\begin{array}{l}\text { Nào, estabelecido como pré } \\
\text { exigência para atuar na área. }\end{array}$ & $\begin{array}{l}\text { Sim, oferta de MBA em } \\
\text { Gerenciamento de Projetos. }\end{array}$ & $\begin{array}{l}\text { Nào, estabelecida como } \\
\text { préexigência para atuar } \\
\text { na área. }\end{array}$ \\
\hline & Atividades realizadas & Em dupla & Individualmente & Individualmente \\
\hline & $\begin{array}{l}\text { Gestão de RH: recursos } \\
\text { de gestão- estimulos e } \\
\text { desempenho }\end{array}$ & $\begin{array}{l}\text { Meritocracia (por equipes } / 14^{\circ} \\
\text { salário); worksbops com trocas } \\
\text { de experiências; estimulo à } \\
\text { inovação e produção científica } \\
\text { (trabalhos). }\end{array}$ & $\begin{array}{c}\text { Worksbops com trocas de } \\
\text { experiências }\end{array}$ & Worksbops \\
\hline & Difusão da metodologia & $\begin{array}{l}\text { Para as pontas nos órgãos } \\
\text { executivos do estado (EGP } \\
\text { setorial) }\end{array}$ & $\begin{array}{l}\text { Para as pontas nos órgãos } \\
\text { executivos do estado (EGP } \\
\text { setorial) }\end{array}$ & $\begin{array}{c}\text { Para as pontas nos } \\
\text { orgãos executivos do } \\
\text { estado (EGPsetorial) e } \\
\text { prefeituras }\end{array}$ \\
\hline \multirow{4}{*}{ 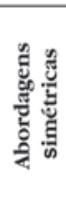 } & $\begin{array}{l}\text { Sistema de } \\
\text { acompanhamento }\end{array}$ & \multicolumn{3}{|c|}{ Software-status report } \\
\hline & Metodologia empregada & \multicolumn{3}{|c|}{$\begin{array}{r}\text { Aderente ao } \\
\text { PMBOK } / \text { PMI }^{*}\end{array}$} \\
\hline & Função & \multicolumn{3}{|c|}{ Acompanhar carteira de projetos. } \\
\hline & $\begin{array}{l}\text { Função do sistema de } \\
\text { acompanhamento }\end{array}$ & \multicolumn{3}{|c|}{ Medir execução (metas e marcos) e sinalizar progresso ou atraso. } \\
\hline
\end{tabular}

Fonte: Elaborado pelo primeiro autor 
Destacam-se as falas: a disponibilidade de recursos financeiros é uma questão crítica para o sucesso de qualquer iniciativa dentro da administração pública, e são os projetos que buscam o alcance da estratégia, dos objetivos do governo.

A terceira questão aborda a perspectiva dos governos de serem mais estratégicos e executivos nas suas políticas de gestão, orientando-se para resultados de desenvolvimento. Nesse caso, procura-se saber como os entrevistados avaliam o uso da metodologia de gerenciamento de projetos. Sob a perspectiva de explorar o uso de técnicas, ferramentas, modelos e procedimentos aludidos pelo gerenciamento de projetos, buscou-se entender como se dá tal contribuição. As falas dos entrevistados denotam o emprego e a contribuição da metodologia de gerenciamento de projetos: praticamente todas as implementações de políticas públicas são "projetizadas" e, de maneira geral, o gerenciamento de projetos tem sido visto como grande inovação na gestão pública. Essa aceitação está diretamente relacionada à maior capacidade de prover os resultados, principalmente no âmbito dos custos e dos prazos previstos.

A quarta questão é referente à contribuição do escritório de gerenciamento de projetos para o alcance dos resultados do governo. Dentre as falas, destaca-se que o EGP possibilita algumas coisas das quais não se pode desconectar, pois permite saber em que ritmo você está andando, acompanhar um cronograma e, assim, identificar possíveis desvios (tanto de marcos quanto de metas); também é importante a organização da informação que fica disponível ao governo, mais precisamente ao alcance dos tomadores de decisão, e a contribuição é traduzida em mais e melhores entregas, com gasto mais inteligente.
A quinta pergunta coloca em xeque o uso dos recursos do gerenciamento de projetos e questiona sobre a viabilidade de implementação dos projetos públicos. Ciente de que as administrações públicas sempre se utilizaram de recursos públicos para fazer obras, implantar benefícios visando progresso e prosperidade das civilizações, a pergunta explora a não disposição dos aludidos recursos de gestão, haja vista que inúmeras administrações desconhecem esse

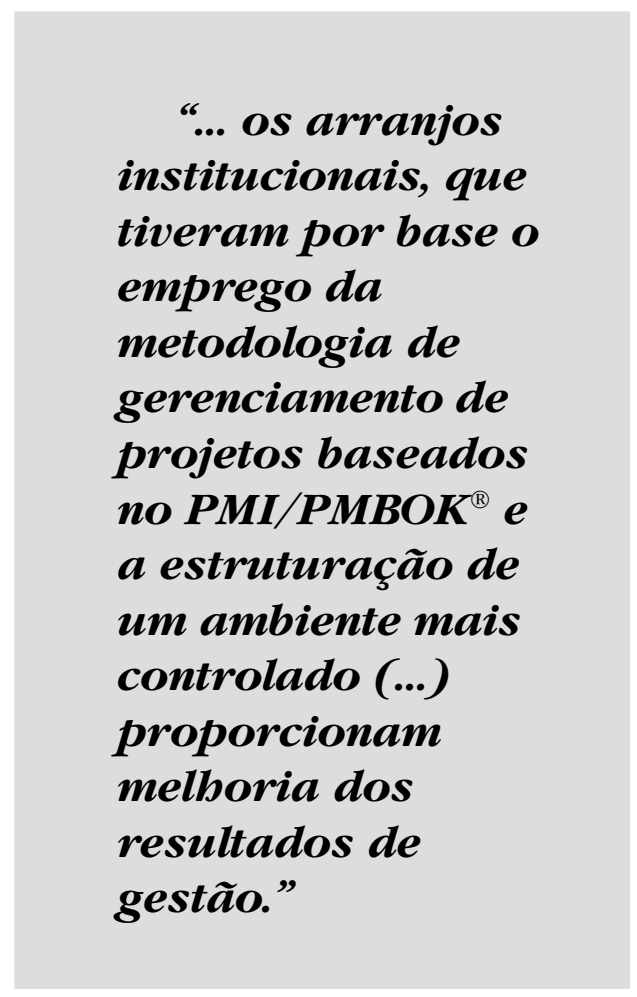

conjunto de conhecimentos, técnicas e ferramentas. Destacam-se: as soluções seriam menos qualificadas; o que o gerenciamento de projetos faz é conseguir qualificar o caminho; e quem conseguir adaptar a metodologia de gerenciamento para os projetos públicos terá mais êxitos do que aqueles que pensam em somente materializar projetos, apesar de sempre ter havido 
a implantação de projetos, talvez não dentro dos resultados esperados. Acredita-se que a viabilidade da implementação dos projetos públicos recaia muito sobre a habilidade, experiência e competência do gestor ou sobre a capacidade técnica de determinado grupo de indivíduos.

A sexta e última pergunta da entrevista questionou a contribuição da gestão do desempenho para o alcance dos objetivos e metas de resultado do governo. Apenas no Governo do Estado de Minas Gerais é possível afirmar que há uma política definida de recursos humanos que considera a gestão do desempenho. Nesse caso, destacam-se as seguintes falas: a gestão do desempenho deve ser moldada de forma a direcionar e alinhar as pessoas e as organizações para os resultados que o governo pretende alcançar, e a conscientização da meta, do desafio do resultado contribui para comprometer as pessoas; nesse processo, há convergência de fatores que contribuem para os resultados, pois envolvem pessoas sensibilizadas.

Quanto ao questionário de recursos utilizados no gerenciamento de projetos públicos, que foi respondido pelas equipes de técnicos que estão à frente do gerenciamento dos projetos - em nível de escritório central de gerenciamento de projetos (EGP) -, a tabulação foi realizada considerando o conhecimento ou o desconhecimento das técnicas, processos e ferramentas listadas, assim como sua aplicação. Citaram que utilizam rotineiramente os processos: desenvolvimento do cronograma, estimativa de custos, estimativa de duração da atividade, orientar e gerenciar a execução do projeto, e relatório de desempenho. Quanto às ferramentas, disseram que habitualmente utilizam: cronograma de marcos, cronograma mestre, modelo de cronograma, sistema de gerenciamento de projetos e software de gerenciamento de projetos.

\section{Considerações finais}

Após a experiência de interatividade com os governos pesquisados, coleta de dados, conversas informais e entrevistas, pôde-se chegar a algumas deduções pertinentes ao objeto de estudo e a particularidades de cada governo central, quanto à implementação de suas políticas públicas, sob o modelo de gerenciamento de projetos públicos.

As tentativas de falseamento não surtiram efeito, visto que os respondentes dos questionários e os entrevistados reafirmaram os conceitos balizadores, sustentando a hipótese conjecturada. É possível inferir que, apesar das diferenças apresentadas, os três governos adotaram a metodologia de gerenciamento de projetos com intuito de viabilizar a implementação das estratégias, tanto a do plano de governo (referenciado na campanha política) quanto a do planejamento estratégico de longo prazo.

A Figura 2 resume os fatores que influenciam a melhoria da eficiência e somam para melhorar a eficácia no alcance dos resultados de gestão governamental.

Sendo assim, é possível considerar, com base nos dados coletados e analisados, que o escritório de gerenciamento de projetos públicos é um instrumento importante e robusto da gestão orientada para resultados, pois contribui para que tais projetos sejam implementados com grande chance de êxito. Os resultados obtidos no estudo corroboram a hipótese conjecturada, pois mostram que os arranjos institucionais, que tiveram por base o emprego da metodologia de gerenciamento de projetos baseados no $\mathrm{PMI} / \mathrm{PMBOK},{ }^{\circledR}$ e a estruturação de um ambiente mais controlado, caracterizado pela 


\section{Melhoria da eficiência da implementação Fatores identificados no estudo}

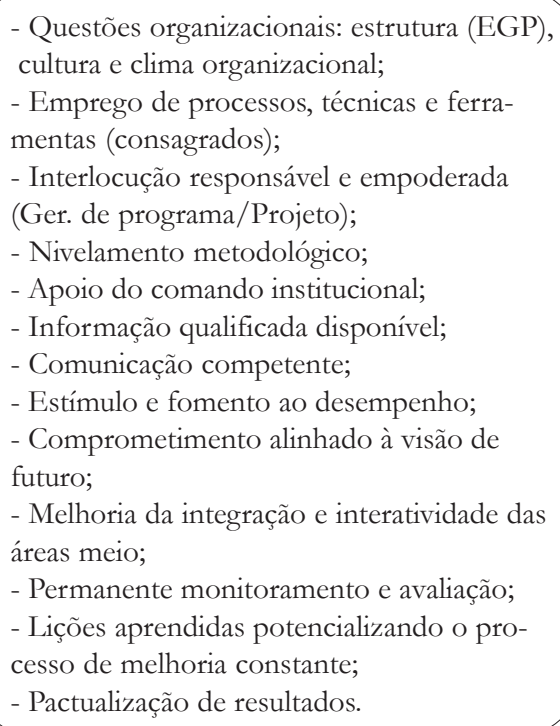

Fonte: Elaborada pelo primeiro autor

\section{Figura 2: Ilustração da convergência de fatores aliados à eficiência que favorecem a eficácia dos resultados de gestão}

implantação do escritório de gerenciamento de projetos públicos, proporcionam melhoria dos resultados de gestão, pois ampliaram a eficiência do processo, contribuindo para a melhoria da eficácia, traduzida pelo melhor atingimento das metas de gestão.

Porém, o emprego dessa metodologia, como o de qualquer outra, requer pessoas qualificadas e sensibilizadas, gestores conscientes e capazes de sustentar a incorporação do emprego de recursos novos, que na maioria das vezes mexem com a cultura e o clima organizacional. A fronteira entre o sucesso e o fracasso é tênue e se dá por questões intangíveis. Portanto, lograr êxito com a adoção de novos recursos de gestão requer o enfrentamento de fatores paradigmáticos, comuns às organizações.

Cabe salientar alguns limites que requerem atenção dos governos ao empregarem tais recursos para a implementação de suas políticas públicas:

- A atenção ao escopo dos projetos, uma vez que situações adversas e não planejadas podem exigir a revisão do escopo, e, sendo os projetos públicos passivos de variados controles, cabe observar a necessária condição de prover a flexibilização, visando atender à efetividade dos objetivos propostos.

- O gerenciamento das comunicações é fundamental para o êxito dos projetos por um cabedal de motivos já difundidos pela literatura; mas cabe observar que, 
nesse sentido, o volume é menos importante que a qualidade e o correto direcionamento, havendo necessidade de prover uma atenção especial quanto à arquitetura do processo de geração de informações, análise e distribuição.

- O conflito e o embate entre políticos e burocratas não devem ser balizados por interesses individuais e, sim, pelo atendimento aos preceitos que melhor atendam aos cidadãos beneficiados.

- O avanço da transparência e do controle social certamente requererá uma melhor tradução dos termos mais técnicos, a fim de criar uma linguagem acessível à compreensão dos cidadãos, situação que concorrerá para a boa compreensão do processo de implementação dos programas e projetos governamentais.

Sendo assim, sugere-se aos governos que objetivem orientar-se para resultados, o que se caracteriza principalmente pela adesão ao modelo aberto de gestão para resultados do BID/Clad, que considerem em sua estrutura organizacional a instalação do escritório de gerenciamento de projetos. Tal instalação visa introduzir os principais elementos de sustentação que proporcionam melhorar o controle sobre o ambiente em que se gerenciam os projetos e, também, promover a disseminação da metodologia para os demais órgãos da administração pública, independentemente da função, pois o modelo se comporta como elemento que melhora a performance na exequibilidade dos projetos institucionais.

Tais recursos poderão auxiliar os técnicos e os gestores que lidam com a implantação de programas e projetos públicos, possibilitando assim melhor desempenho na implementação das políticas públicas de gestão em todas as esferas de governo.

(Artigo recebido em fevereiro de 2012. Versão final em maio de 2012).

\section{Referências bibliográficas}

ABrucio, Fernando Luiz. O impacto do modelo gerencial na administração pública: um breve estudo sobre a experiência internacional recente. Brasília, Enap, Cadernos Enap, n.10, p. 6-49, 1997.

Abrucio, Fernando Luiz; GaEtani, Francisco. Avanços e perspectivas da gestão pública nos estados: agenda, aprendizado e coalizão. In: Consad - Conselho Nacional de Secretários de Gestão. Avanços e Perspectivas da Gestão Pública nos Estados. São Paulo: Fundap, 2006. Aucoln, Peter. The New Public Management: Canada in Comparative Perspective. Montreal: IRPP, 1995.

BID (Banco Interamericano de Desenvolvimeto) \& CLAD (Centro Latinoamericano de Administracion para el Desarrollo). Modelo abierto de gestión para resultados en el sector público. In: Documentos debate del CLAD: Estado Administración Públicay Sociedad, n.11, 2007.

BrASIL. Lei no 8.666, de 21 de junho de 1993. Regulamenta o art. 37, inciso XXI, da Constituição Federal, institui normas para licitações e contratos da Administração Pública e dá outras providências. Diário Oficial da União, Brasília, DF, 22 de junho de 1993. Seção 1, p. 8269. Republicada no Diário Oficial da União, 6 de julho de 1994. 
Brasil. Lei Complementar no 101, de 04 de maio de 2000. Estabelece normas de finanças públicas voltadas para a responsabilidade na gestão fiscal e dá outras providências. Diário Oficial da União, Brasília, DF, 05 de maio de 2000. Seção 1, p. 1.

Bresser Pereira, Luis Carlos. Instituições, Bom Estado e Reforma da Gestão Pública. Revista Eletrônica sobre a Reforma do Estado (RERE), n 1, Instituto de Direito Público da Bahia, Salvador/BA, 2005.

Cohen, Ernesto; Franco, Rolando. Avaliação de projetos sociais. Petrópolis. Editora Vozes, $6^{a}$ Ed., 2004.

CoтA, Marcelo Foresti Matheus. A influência do escritório de gerenciamento de projetos no desenvolvimento de competências do gerente de projetos. 2011. 211 f. Tese (Doutorado em Administração) - Departamento de Administração da Faculdade de Economia, Administração e Contabilidade, Universidade de São Paulo, São Paulo.

Hood, Christopher. The New Public Management in the 1980s: variations on a theme. Accountability, Organizations and Society, v. 20, 1995.

Martins, Humberto Falcão. Administração para o Desenvolvimento: a relevância em busca da disciplina. Revista do Consad, Ano 1, n. 1, abril 2004.

Perdicaris, Priscilla Reinich. Alcances e limites da Gestão para Resultados: experiências brasileiras. III CONGRESSO CONSAD DE GESTÃO PÚBLICA, 2009, Brasília.

PMBOK $/$ PMI ${ }^{\circledR}$ - Project Management Institute. Um Guia do Conjunto de Conhecimentos em

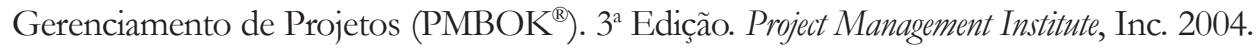

PMBOK $/ \mathrm{PMI}^{\circledR}$ - Project Management Institute. Government Extension to the PMBOK ${ }^{\circledR}$ guide third Edition. Four Campus Boulevard, Newtown Square, PA. 2006.

Pollitt, Christopher; Bouckaert, Geert. Avaliando reformas da gestão pública: uma perspectiva internacional. Revista do Serviço Público, v. 53, 2002.

Rosa, Marcelo Ozorio. Gerenciamento de Projetos em Instituições Públicas. PMInforma, PMI-DF, n. V, maio 2007.

SERRA, Alberto. Modelo aberto de gestão para resultados no setorpúblico. Tradução de Ernesto MontesBradley y Estayes. Universidade Federal do Rio Grande do Norte. 140 p. Natal, 2008.

SILVA, Mônica Aparecida Rocha da. A institucionalização da Avaliação da Educação Superior: uma análise comparativa do Brasil e do México. 2007. 215 f. Tese (Doutorado em Ciências Socias) - Instituto de Ciências Sociais, Universidade de Brasília, Brasília. 


\section{Resumo - Resumen - Abstract}

\section{Contribuições do escritório de gerenciamento de projetos públicos na gestão para} resultados

Marcelo Torres Pinheiro e Mônica Aparecida da Silva Rocha

Gerenciamento de projetos (GP) e gestão para resultados (GpR) são temas que vêm ganhando espaço nas administrações públicas. Entre as recomendações do modelo aberto de gestão para resultados do Banco Interamericano de Desenvolvimento (BID) e do Centro Latinoamericano de Administração para Desenvolvimento (Clad), está a gestão de programas e projetos. A interação entre tais temas instigou o trabalho de pesquisa, que teve o propósito de compreender a sinergia entre a metodologia de GP do Project Management Institute e o referido modelo aberto, ou seja, de que maneira técnicas, processos e ferramentas de gerenciamento de projetos contribuem para a GpR. As relações foram pesquisadas a partir de três escritórios de gerenciamento de projetos (EGP) de governos estaduais. Com base no método hipotéticodedutivo foram aplicados questionários, realizadas entrevistas e coletados materiais in loco. Os EGP, apesar de possuírem funções correlatas, têm especificidades distintas. Os resultados da investigação sugerem que o GP impacta no processo de planejamento e implementação de políticas públicas, atuando, sobretudo, na melhoria da eficiência e da eficácia das práticas da gestão governamental.

Palavras-chave: Gerenciamento de projetos públicos, gestão para resultados, implementação de políticas públicas

\section{Contribuciones de la oficina de dirección de proyectos públicos en la gestión por resultados}

Marcelo Torres Pinheiro y Mônica Aparecida da Silva Rocha

Dirección de proyecto (DP) y gestión por resultados (GpR) son temas que han ido ganando terreno en el gobierno. Entre las recomendaciones del modelo abierto para la gestión por resultados del Banco Interamericano de Desarrollo (BID) y el Centro Latinoamericano de Administración para el Desarrollo (Clad) está la gestión de programas y proyectos. La interacción de estos temas ha instigado el trabajo de investigación, que tenía el propósito de comprender la sinergia entre la metodología de GP del Project Management Institute y el modelo abierto mencionado, o sea, de que modo técnicas, procesos y herramientas de gestión de proyectos contribuyen para la gestión por resultados. Las relaciones fueron estudiadas en tres oficinas de gestión de proyectos (OGP) de los gobiernos estatales. Basado en el método hipotético-deductivo se aplicaron cuestionarios, se realizaron entrevistas y se recogieron materiales en el lugar. El OGP, a pesar de presentar las mismas funciones, tienen especificidades distintas. Los resultados de la investigación sugieren que el GP afecta el proceso de planificación e implementación de políticas públicas, trabajando principalmente en la mejora de la eficiencia y la eficacia de las prácticas de gestión gubernamental.

Palabras clave: Gestión de proyectos públicos, gestión por resultados, implementación de políticas públicas 


\section{A public project management office's contribution to result managing system}

Marcelo Torres Pinheiro and Mônica Aparecida da Silva Rocha

Project Management (PM) and Managing for Results (MFR) are issues that have been gaining ground among government institutions. Management of programs and projects is one of the recommendations from the open model results for Inter-American Development Bank (IDB) and the Latin American Centre for Development Administration (Clad). The interaction between these issues incited the research work, which had the purpose of understanding the synergy between the PM methodology from the Project Management Institute and the open model previously mentioned. In which manner do the techniques, processes and tools of project management contribute to the Managing for Results? Relations were surveyed from three Project Management Offices (PMO) of state governments. Based on the hypothetical-deductive method, questionnaires, interviews and materials collected on the spot were applied. The PMO's, despite sharing the same functions, have different specificities. Research results suggest that the PM impacts the process of planning and implementation of public policies, working mainly on improving the efficiency and effectiveness of government management practices.

Keywords: Public project management, managing for results, public policy implementation

Marcelo Torres Pinheiro

Mestre em Desenvolvimento Regional pela Universidade Federal do Tocantins (UFT). Professor de Administração da Faculdade Serra do Carmo (FASEC). Contato: martopin@uol.com.br

Mônica Aparecida da Rocha Silva

Doutora em Ciências Sociais pela Universidade de Brasília (UNB). Professora do programa de pós-graduação em Desenvolvimento Regional da Universidade Federal do Tocantins (UFT).Contato: monicars@uft.edu.br 